\title{
Achievement Motivation of Children of Employed Mothers and Homemakers
}

\author{
Dr. Anu Dandona ${ }^{1} *$
}

\section{ABSTRACT}

Ever since women began entering the work force the debate has been looming over mothers who enter the work force and those who choose to remain at home with their children. Such concerns are whether or not having a working mother negatively affects their children emotionally and/or academically. Another concern is the stress level a working mother faces daily. The present study assessed the impact of maternal employment on achievement motivation of adolescents. The sample consisted of 80 children of employed mothers and 80 children of homemakers. Further the sample was bifurcated on the basis of gender (40 boys and 40 girls). Costello Achievement Motivation Scale (CAMS) adapted by Misra, O.P \& Srivastava, S.K, 1990was administered to the selected sample to assess their achievement motivation. The obtained data was treated with the help of Mean, SD, t-test and ANOVA. Analysis of the results revealed that children of employed mothers had higher achievement motivation as compared to the children of homemakers. Further, findings indicated that adolescent girls of employed mothers scored higher on achievement motivation as compared to adolescent boys of homemakers.

Keywords: Achievement Motivation, Employed mothers, homemakers, Adolescent boys, Adolescent girls.

Adolescence is one of the important periods of life. It is characterized by innumerable and unique. Motivation can be defined as the driving force behind all the actions of an individual. The influence of an individual's needs and desires both have a strong impact on the direction of their behaviour. Motivation is based on emotions and achievement related goals. There are different forms of motivation including extrinsic, intrinsic, and psychological and achievement motivation. There are also more negative forms of motivation can be defined as the need for success or the attainment of excellence. Individuals will satisfy their needs through different means, and are driven to succeed for varying reasons both internal and external. Family, which plays an important role in the personality development of adolescents, is undergoing structural, emotional and interactional transformations. There is a great contribution of mothers in shaping

\footnotetext{
${ }^{1}$ Assistant Professor, AIBAS, Amity University, Lucknow, India

*Responding Author

(c) 2016 I A Dandona; licensee IJIP. This is an Open Access Research distributed under the terms of the Creative Commons Attribution License (http://creativecommons.org/licenses/by/2.0), which permits unrestricted use, distribution, and reproduction in any Medium, provided the original work is properly cited.
} 


\section{Achievement Motivation of Children of Employed Mothers and Homemakers}

the personality of their children. In recent years owing to spread of education, search of the identity and introduction of technological changes, increasingly large number of women in India is entering in the job market. Rapid expansion in women's education in the post-independence period has improved the possibility of their employment. Today there is no profession in which women have not entered. This has led to radical shift in the traditional role of mother as a "care taker" to a "bread earner" and has altered child rearing goals and practices. Hence, an attempt is made to see the effects of it on achievement motivation of their adolescents.

A working mother can be defined as any woman who works outside the home and has children. Whereas, a homemaker is the one who has children but does not work outside the home. Working mothers and homemakers affect their children in different ways because of their different dynamics.

Achievement motivation have been considered as an extended person- intrinsic motivation showing a pattern of actions, planning and feelings connected with striving to achieve some internalized standards of excellence. Need for achievement has been regarded as an individual's personality affective person's behaviour. It is also regarded as a learned motivation.

Achievement Motivation is the attitude to achieve rather than the achievements themselves. It can be considered as extended person-intrinsic motivation because its reinforcement is delayed. It arises from an interaction within the person. Achievement motivation is "a pattern of planning of actions and of feelings connected with striving to achieve some internalized standard of excellence, as contrasted for example, will power or friendship” As academic achievement is not a function of cognitive variable alone the emphatic stress on the contribution of the psychological variable is imperative. As such this of the psychological variable is of prime importance, what percentage of proportion variance is attributable by them towards the criteria, needs elaboration and quantification.

A mother is particularly important not because she has special skills but because she is with her children for a much greater time than any other person and her instructions reflects a very strong influence on attitudes, abilities and behaviour of children. Most of those children who are successful and well-adjusted come from homes where parental attitudes are favourable and a wholesome relationship existed between children and parents (Aeri, P. and Jain, D. 2010). According to Lyn Crage (2006), those mothers who are high educated and working are more sensitive to their children.

Hangal S. \&Aminabhavi, V. A.(2007) have found that the adolescent children of home makers have significantly higher self-concept. The children of home makers have significantly higher self-concept and higher achievement motivation than the children of employed mothers. The female children of home makers are having significantly higher emotional maturity compared to the male children of home makers. The children of employed mothers are more socially maladjusted and lacked independence to a very highly significant level compared to the children of home makers. Hock, McBride \& Gnezda (2004) have revealed that there existed a positive 


\section{Achievement Motivation of Children of Employed Mothers and Homemakers}

relation between maternal separation anxiety and children's anxieties and separation from their mothers. This is perceived as a threat to the child's well-being and/or to her own psychological equilibrium. Such anxiety may be reflected in feelings of worry, sadness, or guilt.

Since working mothers spend a substantial amount of time outside home, they try to give their children quality time in which they can nurture them. It is exclusively children's time. However things are a little different for homemakers. They do spend more time with their children but that time is not necessarily quality time because they simultaneously have to look after the children and do the household chores. The topic of this research is to study how mother's employment or unemployment affects their children's achievement motivation.

\section{OBJECTIVES}

There are five main objectives studied in this paper:

1. To compare the achievement motivation of children of employed mothers and homemakers.

2. To compare the achievement motivation of sons of employed mothers and homemakers.

3. To compare the achievement motivation of daughters of employed mothers and homemakers.

4. To compare the achievement motivation of sons and daughters of employed mothers.

5. To compare the achievement motivation of adolescent boys and girls.

\section{Hypotheses:}

The following hypotheses were framed for the purpose of present study:

1. There will be no significant difference on achievement motivation of children of employed mothers and homemakers.

2. There will be no significant difference on achievement motivation of sons of employed mothers and homemakers.

3. There will be no significant difference on achievement motivation of daughters of employed mothers and homemakers.

4. There will be no significant difference on achievement motivation of sons and daughters of employed mothers.

5. There will be no significant difference on achievement motivation of adolescent boys and girls.

\section{METHOD}

\section{Sample}

Total sample comprised of 160 adolescents, 80 children of employed mothers and 80 children of home-makers were included in the sample. Further, sample was bifurcated according to gender (40 girls and 40 boys). The adolescents studying in 11th and 12th standard in the age range of 17 to 19 years were selected from different schools of Delhi. 
Table 1: Gender wise distribution of the sample

\begin{tabular}{|l|l|l|l|}
\hline Employed Mothers & Home Makers \\
\hline Boys & Girls & Boys & Girls \\
\hline 40 & 40 & 40 & 40 \\
\hline Total $=80$ & Total=80 & \\
\hline
\end{tabular}

\section{Tools Used}

(a) The personal data sheet was prepared to collect the information regarding student's age, standard (class), gender, their mother's qualification, mother's employment status etc.

(b) Costello achievement motivation scale (CAMS-adapted by Misra, O.P \& Srivastava, S.K, 1990)was used to assess achievement motivation of children. It consists of 24 items, which can be answered by making a tick $(\sqrt{ })$ mark under "Yes" or "No" category. Question no. 2,3,5,7,9,11,13,17,19,20,22 and 24 are given one mark if answered positively by the subject. These items will be assigned zero if answered in negative manner. Likewise item no. 1,4,6,8,10,12,14,15,16,18,21, and 23 are awarded one mark if answered in negative manner. These items are assigned zero if answered in positive manner. Maximum possible score is 24. A high score reflects high achievement motivation.

\section{Statistical Analysis}

The collected data were classified and tabulated in accordance with the objectives to arrive at the meaningful and relevant inferences by using arithmetic mean, standard deviation, t-test and ANOVA.

\section{RESULTS AND INTERPRETATION}

To examine the significance of difference between children of employed mothers and homemakers on their achievement motivation, obtained data was treated with the help of Mean, $\mathrm{SD}$, t-test and Analysis of variance (2x2) statistical techniques. The outcomes of the analysis are presented in the tables (table 2, 3, 4, 5, 6 and 7).

Table 2: Mean, SD and $t$ values for achievement motivation of children of employed mothers and homemakers.

\begin{tabular}{|l|l|l|l|l|}
\hline Children & N & Mean & Std. Deviation & t \\
\hline Employed mothers & 80 & 16.72 & 2.66 & $2.71^{* *}$ \\
\hline Homemakers & 80 & 15.69 & 2.156 & \\
\hline
\end{tabular}

Table 2 shows significant difference between the children of employed mothers and homemakers on their achievement motivation $(\mathrm{t}=2.71, \mathrm{p}<0.01)$. The Mean values of the children of employed mothers and homemakers son achievement motivation are 16.72 and 15.69 respectively. It reveals that the children of employed mothers are having high achievement motivation than the children of homemakers. Hence, Null hypothesis is rejected. 
Table 3: Means, SDs and $t$ values of Sons of employed and non-employed mothers on achievement motivation

\begin{tabular}{|l|l|l|l|l|}
\hline Sons & N & Mean & Std. Deviation & t \\
\hline Employed Mothers & 40 & 15.65 & 2.38 & \\
\hline Homemakers & 40 & 15.32 & 2.08 & .650 \\
\hline
\end{tabular}

The comparison of scores of sons of employed mothers and homemakers on achievement motivation is performed in the table 3, which shows that there is non-significant difference between sons of employed mothers and homemakers on achievement motivation ( $t=.650)$. Hence, Null hypothesis is not rejected.

Table 4: Mean, SD and t values of Daughters of employed mothers and homemakers on achievement motivation

\begin{tabular}{|l|l|l|l|l|}
\hline Daughters & N & Mean & SD & t \\
\hline Employed Mothers & 40 & 17.80 & 2.50 & \multirow{3}{*}{$3.32^{* *}$} \\
\hline Homemakers & 40 & 16.05 & 2.19 & \\
\hline
\end{tabular}

Table 4 indicates that daughters of employed mothers and homemakers differ significantly on achievement motivation. The obtained t-value(3.32) is significant at 0.01 level. The mean values of the daughters of employed mothers and homemakers on achievement motivation are 17.80 and 16.05 respectively. It means that daughters of employed mothers are having high achievement motivation as compared to the daughters of homemakers. Hence, Null hypothesis is rejected.

Table 5:Mean, SD and t values of Sons and Daughters of employed mothers on achievement motivation

\begin{tabular}{|l|l|l|l|l|}
\hline Gender & N & Mean & SD & t \\
\hline Girls & 40 & 17.80 & 2.50 & \\
\hline Boys & 40 & 15.65 & 2.38 & $3.94^{* *}$ \\
\hline
\end{tabular}

Table 5 shows that there are significant differences between sons and daughters of employed mothers regarding their achievement motivation as the obtained t-value (3.94) is significant at 0.01 level. The Mean values of daughters and sons of employed mothers on the achievement motivation are 17.80 and 15.65 respectively. It reveals that the daughters of employed mothers scored higher on achievement motivation as compared to the sons of employed mothers. Hence it leads to rejection of the null hypotheses. 
Table 6:Mean, SD and t values of Sons and Daughters of homemakers on achievement motivation

\begin{tabular}{|l|l|l|l|l|}
\hline Gender & N & Mean & SD & t \\
\hline Girls & 40 & 16.05 & 2.19 & \\
\cline { 1 - 4 } Boys & 40 & 15.32 & 2.08 & 1.51 \\
\hline
\end{tabular}

The comparison of scores of sons and daughters of homemakers on achievement motivation is performed in the table 3, which shows that there is non-significant difference between sons and daughters of homemakers on achievement motivation $(t=1.51)$. Hence, Null hypothesis is not rejected.

Table 7: 2x2 ANOVA on achievement motivation of children of employed and unemployed mothers.

\begin{tabular}{|l|l|l|l|l|}
\hline Source & Sum of Squares & df & Mean Square & F \\
\hline Mothers & 43.056 & 1 & 43.056 & $8.17^{* *}$ \\
\hline Gender & 82.656 & 1 & 82.656 & $15.68^{* *}$ \\
\hline Mothers * Gender & 20.306 & 1 & 20.306 & 3.85 \\
\hline Error & 822.175 & 156 & 5.270 & \\
\hline
\end{tabular}

The mean score of mothers (employed and homemakers) with gender (boys and girls) was analysed by $2 \times 2$ factorial design (table 6). A significant difference was found for mothers (employed and homemakers) and gender. It is observed that the mothers having $\mathrm{F}$ value 8.17 and gender $(\mathrm{F}=15.68)$ are significant at 0.01 level of confidence. It indicates that difference in mothers (employed and homemakers) and gender affects the achievement motivation. The interactional $\mathrm{F}$ value (3.85 df 1 and 156) (mothers $\mathrm{x}$ gender) is not significant at any level of confidence.

\section{DISCUSSION}

The purpose of this study was to examine the achievement motivation of children of employed mothers and homemakers. The result showed that the achievement motivation is higher for children of employed mothers than children of homemakers (table-2).In table $3 \& 4$, comparison of employed mothers and homemakers in respect of gender separately, results showed girls of employed mothers and homemakers differ on achievement motivation and girls of employed mothers are higher on achievement motivation in contrast to girls of homemakers. Furthermore, no significant difference exists between boys of employed mothers and home makers. Mancini and Pasqua (2012) have studied on mothers' actual time spending with their children. Results shown that working mothers, with respect to non-working ones, tend to reduce the "basic care" time, but not "quality care" time devoted to their children (reading stories or helping them with homework, taking their children to a museum or to theatre). Therefore, even if working, they may be able not to reduce the time devoted to activities which are more likely to positively 


\section{Achievement Motivation of Children of Employed Mothers and Homemakers}

influence the school results of their children. Saini (2005) conducted a study on family environment and academic achievement of children of working and nonworking mothers. Major findings of the study revealed that children of working mothers were more independent than children of non-working mothers and children of working mothers were higher in academic score than those of the children of non-working mothers. A research study by Sharma and Sharma (2010) also states that the only child of working mothers has higher need for achievement as compared to those whose mothers were not working. Goswami, M. (2000) conducted a study on Achievement Motivation and Anxiety among the Children of Working and Non-working Mothers Studying in Secondary Schools of Shillong. The findings indicated that children of working mothers were more achievement oriented than the children of non-working mothers.

Since the relationship with mother is the most significant relationship, it has the power to influence individuals strongly in many areas of life. Also in our culture and religion mother is highly regarded and we are inclined to follow in the footsteps of the mother. Therefore the higher need for achievement in the children of working mothers can be explained with reference to the mother-as-a-role-model theory (Hoffman, 1998). That is, the children of working mothers see their own mothers as their role models and in an attempt to be like her they have a higher need for achievement. They aspire to be like their mothers by being better at academics, succeeding in their careers and they also set their goals higher and work hard to achieve them. However for children of nonworking mothers, their mother-as-a-role model in terms of career is absent.

Quality of mothering is another factor that might contribute to the high need for achievement in children of working mothers. Working mothers might encourage their children to become more self-sufficient and independent at an earlier age and this early independence training may be translated into high need for achievement and competence (Ahmad, 2002). In our culture and country since traditionally men work outside home and mothers stay at home, so the working-mother-as-a-role model theory can be used as an explanation to explain the results of this study. Children of working mothers tend to see their mothers as role models and thus have a higher need for achievement. Also working mothers tend to give their children quality time and parenting which might affect their need for achievement. They might be more actively involved in their children's academic activities. Hangal and Aminabhavi (2007) assessed the impact of maternal employment on the Self-concept, Emotional Maturity and Achievement Motivation of the Adolescents children of Employed mothers and Home makers. The results revealed that the adolescent children of homemakers have significantly higher self-concept. It was also noticed that children of employed mothers have high emotional maturity and female children of employed mothers are highly achievement oriented.

Analysis of table-5 showed that girls and boys of employed mothers differ significantly from each other on achievement motivation and girls of employed mothers possess high achievement 


\section{Achievement Motivation of Children of Employed Mothers and Homemakers}

motivation as compared to boys of employed mothers. Linnenbrink and Pintrich (2002) examined research pertaining to student motivation and four key components that included academic self-efficacy, attributions, intrinsic motivation, and achievement goals. Males and females were found to have different competence-related beliefs during childhood and adolescence (Wigfield \& Eccles, 2002). Results revealed that boys had higher competence beliefs in sports activities and math compared to girls. However, girls had higher competence beliefs in reading, English, and social activities compared to boys. Linnenbrink and Pintrich posited that competence beliefs are important because they predict performance and task choice. These beliefs also affect the student's motivation to succeed and achieve a goal. Other researchers have investigated gender differences in future orientation and motivation (Greene \& DeBacker, 2004). This meta-analysis examined differences in orientation and motivation across several studies. They concluded that females typically pursue a greater array of goals compared to males. Further, Aminabhavi and Hangal (2007) also found out that female children of employed mothers have significantly higher need for achievement as compared to the male children of employed mothers.

\section{CONCLUSION}

1. The findings clearly indicated that maternal employment had positive impact on achievement motivation of their children.

2. Children of employed mothers had higher achievement motivation as compared to the children of homemakers.

3. Daughters of employed mothers scored higher on achievement motivation as compared to the daughters of homemakers.

4. Daughters of employed mothers had higher achievement motivation than the sons of employed mothers.

\section{RECOMMENDATIONS}

Additional research can be conducted to study the effects of maternal employment on the children's achievement motivation and other factors that might be contributing to the children's motivation for achievement can be studied.

A study along the same lines can be conducted which can also study parenting style of mother and how it influences the child's achievement motivation for a better understanding of the variables operating behind the achievement motivation of children of employed mothers and homemakers.

\section{REFERENCES}

Aeri, P and Jain, D. (2010). Effect of Employment Status of Mothers on Conceptual Skills of Preschoolers, Journal of Social Sciences, 24(3), 213-215.

Ahmad, Riaz. (2002). Psychological effects upon the children of working mothers in different family structures of Pakistan. Pakistan Research Repository. Retrieved from http://eprints.hec.gov.pk/239/ 
Goswami, M. (2000), Achievement Motivation and anxiety among the children of working and non-working mothers studying in secondary schools of Shillong. Journal of All India Association for Educational Research, Bhubaneswar. (12,1-2,25-28 March June).

Greene, B. A. \& DeBacker, T. K. (2004). Gender and orientations toward the future: Links to motivation. Educational Psychology Review, 16 (2), 91-120.

Hangal S. \&Aminabhavi, V. A. (2007). Self-concept, emotional maturity and achievement motivation of the adolescent children of employed mothers and home makers. Journal of the Indian academy of Applied Psychology 33, 103-110

Hangal, S. and Aminabhavi, V.A (2007). Self- Concept, Emotional Maturity and Achievement Motivation of the Adolescent Children of Employed Mothers and Homemakers. Journal of the Indian Academy of Applied Psychology, 33(1), 103-110.

Hock, E; McBride, S; \& Gnezda, M. 2004. Maternal separation anxiety: mother-mother infant separation from the maternal perspective. Child development, 60, $793-802$.

Hoffman, L. W. (1998). The Effects of the Mother's Employment on the Family and the Child. Parenthood in America. Retrieved from http://parenthood.library.wisc.edu/Hoffman/Hoffman.html

Linnenbrink, E.A., \& Pintrich, P.R. (2002). Motivation as an enabler for academic success. School Psychology Review, 31(3), 313-327.

Lyn Crage (2006). "Parental education, time in paid work and time with children "British Journal of Sociology 57(4) @ London School of Economics and Political Science 200.

Mancini, A.L., \& Pasqua, S. (2012). Asymmetries and Interdependencies in Time Use Between Italian Parents. Applied Economics, 44(32), 4153-4171.

Saini, S. (2005). Family Environment and Academic Achievement of Adolescent Children of Working and Non-Working Mothers. Indian Educational Review, 41(2), 87-95.

Sharma, B., \& Sharma, S. (2010). Emotional profile and need for achievement of the only child of working and non-working mothers. Indian Journal of Social Science Researches, 7 (1),77-82.Retrieved from http://ijssr.110mb.com/ijssr-march-10/11-bharti.pdf

Wigfield, A., \& Eccles, J. S. (2002). Development of achievement motivation. San Diego, CA: Academic Press. 